\title{
The impact of day of surgery on the length of stay for major urological procedures
}

\author{
Gregory J. Nason, MD; Eabhann M. O'Connor, MD; Cathleen O'Neill, MD; Omer Izzeldin, MD; \\ Shane W. Considine, MD; M. Frank O'Brien, MD
}

Department of Urology, Cork University Hospital, Cork, Ireland

Cite as: Can Urol Assoc J 2016;10(11-12):E367-71. http://dx.doi.org/10.5489/cuai.3777 Published online November 10, 2016.

\section{Abstract}

Introduction: Surgery performed later in the week has been associated with longer length of stay (LOS). The aim of this study was to assess if the day of the surgery impacted the LOS for two major urological procedures in a tertiary referral university teaching hospital. Methods: A retrospective review was performed of two major urological procedures consecutively performed by a single surgeon in our unit from March 2012 to December 2015. Patient demographics, histopathological characteristics, operative details, and LOS were obtained from the patients' medical records. Procedures performed on Monday or Tuesday were defined as early in the week and procedures performed on Wednesday, Thursday, or Friday were defined as late in the week.

Results: During the study period, 140 open radical prostatectomy (ORP) and 42 open partial nephrectomy (OPN) procedures were performed. There was a significant difference in median LOS for major urological procedures performed early in the week compared to late in the week (3 [3-4] days vs. 4 [4-5] days; $p=0.0001)$. There was a significant difference in median LOS for ORP performed early in the week compared to late in the week (3 [3-4] days vs. 4 [4-5] days; $p=0.0004)$. There was a similar significant difference in OPN performed early in the week compared to late in the week (4 [3-5.5] days vs. 5 [4-5] days; $p=0.029$ ).

Conclusions: The day of surgery impacts LOS for major urological procedures. Major procedures should be performed early in the week, when it is feasible to facilitate prompt safe discharge and better use of hospital resources.

\section{Introduction}

Many industries operate on a seven-day week basis; however, most hospitals provide routine care on weekdays and only emergency or urgent care at weekends. Hospital staffing levels and paramedical resources are limited on weekends. ${ }^{1}$ As a result, length of stay (LOS) can be impacted by admission later in the week. ${ }^{2}$

Several studies across a variety of surgical specialities, including orthopedic surgery, ${ }^{3,4}$ general surgery, ${ }^{5}$ cardiothor- acic surgery, ${ }^{6}$ plastic surgery, ${ }^{7}$ and gynecology, ${ }^{8}$ have demonstrated that surgery performed early in the week is associated with a shorter LOS. The day of presentation to hospital also impacts outcome and mortality for a variety of serious medical conditions, including chronic obstructive pulmonary disease (COPD), ${ }^{9}$ pulmonary embolus, ${ }^{10}$ myocardial infarction, ${ }^{1,2}$ and heart failure. ${ }^{11}$

Enhanced recovery pathways (ERPs) have remarkably improved postoperative LOS. ${ }^{12,13}$ ERPs define patients' inhospital recovery with set parameters not limited to mobilization, diet, and analgesia. ${ }^{14}$ However ERPs are less adhered to during the weekend due to the reduced working patterns in hospitals and cross-cover by teams that may not have detailed knowledge of the specific ERP. ${ }^{12}$

The aim of this study was to assess if the day of the surgery impacted the LOS for two major urological procedures in a unit with a prescribed ERP for each procedure.

\section{Methods}

A retrospective review was understaken of two major urological procedures performed by a single surgeon in a tertiary referral university teaching hospital from March 2012 to December 2015. Open radical prostatectomy (ORP) and open partial nephrectomy (OPN) were selected as the procedures for the study. These procedures were identified as the two most common major urological procedures performed by the surgeon. This surgeon usually has an operating list on Monday and Wednesday. In our institution, elective operating theatres run from Monday to Friday only; however, the urology ward is a seven-day ward.

Patient demographics, histopathological characteristics, operative details, and LOS were obtained from the patients chart. Procedures performed on Monday or Tuesday were defined as early in the week and procedures performed on Wednesday, Thursday, or Friday were defined as late in the week.

All procedures were performed by a fellowship-trained consultant urologist. A standard radical retropubic prostatectomy was performed via a $10 \mathrm{~cm}$ lower midline incision. A 20 French two-way urinary catheter was left in place for 
two weeks. The pelvic drain was removed once output was $<50 \mathrm{ml} / 24$ hours. A partial nephrectomy was performed via a supra- $11^{\text {th }}$ rib mini-flank small $(8 \mathrm{~cm})$ incision. ${ }^{15}$ The drain was removed once output was $<50 \mathrm{ml} / 24$ hours. All patients follow a departmental ERP with defined minimum requirements prior to discharge. The ERP encourages early mobilization and physiotherapy, recommencement of diet, and conversion to oral analgesia. It also defines criteria for discharge and followup. The ERP was introduced in the unit in October 2011; the study began six months later to allow the new ERP to embed within the daily functions of the multidisciplinary team.

The study was reviewed at the institutional research meeting. Statistical analysis was performed using GraphPad Prism 6.0 using unpaired Student's t-test. A p value of less than 0.05 was deemed statistically significant.

\section{Results}

During the study period, 140 ORP and 42 OPN procedures were performed. Patient demographics and histopathological details are shown in Tables 1 and 2 .

The median LOS for the two major urological procedures together was $4(3-5)$ days. There was a significant difference noted in median LOS for major urological procedures performed early in the week compared to late in the week (3 [3-4] days vs. 4 [4-5] days; $p=0.0001$ ).

The median LOS for ORP was 4 (3-4) days, range 2-11 days (Fig. 1). There was a significant difference in median LOS for ORP performed early in the week compared to late in the week (3 [3-4] days vs. 4 [4-5] days; $p=0.0004$ ) (Table 3). There was variation in LOS noted for radical prostatectomies throughout the series. The first 25 cases were noted to have a shorter LOS compared to the rest $(p=0.012)$ (Table 4). There was no relation between age, prostate-specific antigen (PSA), Gleason grade, or stage and day of surgery for ORP (Table 5).

The median LOS for OPN was 4 (4-5) days, range 3-13 days (Fig. 2). There was also a significant difference in median LOS for OPN performed early in the week compared to late in the week (4 [3-5.5] days vs. 5 [4-5] days; $p=0.029)$ (Table 3$)$. Tumour size $(<4 \mathrm{~cm}$ vs. $>4 \mathrm{~cm})$ at partial nephrectomy was not associated with a difference in LOS (4 [4-5] days vs. 5 [3.5-6] days; $p=0.218$ ). There was no relation between age, sex, side of tumour, size of tumour, or stage and day of surgery for OPN (Table 6).

The 30-day readmission rate was $5 \%(n=7)$. Two patients were readmitted following ORP with superficial wound infections and treated with intravenous antibiotics. One patient was readmitted following ORP with a wound infection and underwent incision and drainage of a rectus sheath abscess. He was treated with intravenous antibiotics and had a vacuum-assisted closure (VAC) dressing applied. Three patients were readmitted with urinomas following OPN and

\begin{tabular}{|c|c|}
\hline $\mathrm{n}$ & 42 \\
\hline Age (Mean \pm SD) & $52.8 \pm 13.1$ \\
\hline \multicolumn{2}{|l|}{ Gender, n (\%) } \\
\hline Male & $24(57.1)$ \\
\hline Female & $18(42.8)$ \\
\hline \multicolumn{2}{|l|}{ Side, n (\%) } \\
\hline Left & $22(52.4)$ \\
\hline Right & $20(47.6)$ \\
\hline Solitary kidney & $4(9.5)$ \\
\hline \multicolumn{2}{|l|}{ Tumour size $(\mathrm{cm})$} \\
\hline Median (IQR) & $3.2(2.4-4.5)$ \\
\hline \multicolumn{2}{|l|}{ Histological subtype, n (\%) } \\
\hline Clear-cell & $26(61.9)$ \\
\hline Papillary & $4(9.5)$ \\
\hline Chromophobe & $3(7.1)$ \\
\hline Oncocytoma & $3(7.1)$ \\
\hline Angiomyolipoma & $2(4.8)$ \\
\hline Benign multiloculated cyst & $3(7.1)$ \\
\hline Cystic nephroma & $1(2.4)$ \\
\hline \multicolumn{2}{|l|}{ Stage, n (\%) } \\
\hline $\mathrm{T} 1 \mathrm{a}$ & $22(66.7)$ \\
\hline $\mathrm{T} 1 \mathrm{~b}$ & $8(24.2)$ \\
\hline $\mathrm{T} 2 \mathrm{a}$ & $1(3)$ \\
\hline $\mathrm{T} 2 \mathrm{~b}$ & $1(3)$ \\
\hline Т3a & $1(3)$ \\
\hline \multicolumn{2}{|l|}{ Length of stay (days) } \\
\hline Median (IQR) & $4(4-5)$ \\
\hline Range & $3-13$ \\
\hline Tumour size $<4 \mathrm{~cm}$ & $4(4-5)$ \\
\hline Tumour size $>4 \mathrm{~cm}$ & $5(3.5-6)$ \\
\hline \multicolumn{2}{|l|}{ Day of week, n (\%) } \\
\hline Monday & $23(54.8)$ \\
\hline Tuesday & $1(2.4)$ \\
\hline Wednesday & $17(40.5)$ \\
\hline Friday & $1(2.4)$ \\
\hline
\end{tabular}

IQR: interquartile range; SD: standard deviation.

had percutaneous drains inserted. None required double-J ureteric stent placement.

There were two mortalities in the series - one patient was readmitted with a wound collection one week following ORP. He had a percutaneous drain inserted to the collection, however, he died suddenly following a collapse on the ward. An autopsy revealed a large pulmonary embolism, despite prophylactic low-molecular-weight heparin and thromboembolic deterrent stockings (TEDS). The second patient died suddenly at home Day 21 post-ORP. Autopsy confirmed ischemic cardiomyopathy, which was not detected during preoperative assessment. 


\begin{tabular}{|c|c|}
\hline $\mathrm{n}$ & 140 \\
\hline Age $($ Mean $\pm S D)$ & $57.48 \pm 5.6$ \\
\hline PSA (ng/mL) & $9.5 \pm 8.4$ \\
\hline \multicolumn{2}{|c|}{ Digital rectal examination, $\mathrm{n}(\%)$} \\
\hline T1c & $68(48.6)$ \\
\hline $\mathrm{T} 2 \mathrm{a}$ & $37(26.4)$ \\
\hline $\mathrm{T} 2 \mathrm{~b}$ & $12(8.6)$ \\
\hline $\mathrm{T} 2 \mathrm{c}$ & $10(7.1)$ \\
\hline T3 & $13(9.3)$ \\
\hline \multicolumn{2}{|c|}{ Radical prostatectomy histopathology } \\
\hline \multicolumn{2}{|c|}{ Gleason grade, $\mathrm{n}(\%)$} \\
\hline $3+3$ & $34(24.3)$ \\
\hline $3+4$ & $62(44.3)$ \\
\hline $4+3$ & $38(27.1)$ \\
\hline $4+4$ & $3(2.1)$ \\
\hline $4+5$ & $2(1.4)$ \\
\hline $5+5$ & $1(0.7)$ \\
\hline \multicolumn{2}{|l|}{ Stage, $\mathrm{n}(\%)$} \\
\hline T2 & $88(62.9)$ \\
\hline T3 & $52(37.1)$ \\
\hline \multicolumn{2}{|c|}{ Length of stay (days) } \\
\hline Median (IQR) & $4(3-4)$ \\
\hline Range & $2-11$ \\
\hline \multicolumn{2}{|l|}{ Day of week, n (\%) } \\
\hline Monday & $75(53.6)$ \\
\hline Tuesday & $3(2.1)$ \\
\hline Wednesday & $61(43.6)$ \\
\hline Friday & $1(0.7)$ \\
\hline
\end{tabular}

\section{Discussion}

Our study demonstrates that day of surgery impacts LOS, with major urological procedures performed later in the week having a significantly longer LOS. There was no difference noted between surgery characteristics (age, sex, stage, size, PSA) and day of surgery (early vs. late) for either procedure studied. Therefore, we would recommend major procedures be performed earlier in the week, if possible. Safe, prompt discharge of patients allows patients to recover outside of hospital in their own environment without the risk of further nosocomial infections and allows more efficient use of hospital resources. Although hospitals are functional at all times, most hospitals have reduced staff levels and less availability of multidisciplinary resources on the weekends. ${ }^{1,2,4,5,9,10,12}$

This finding has been demonstrated consistently across a variety of surgical specialities. ${ }^{3-8}$ Gilmore et al concluded that the day of surgery was an independent predictor of LOS. ${ }^{5}$ Minimally invasive colectomy has an expected LOS ranging from three to five days; surgery on Monday was associated with a significant decrease in LOS given that patients were predominantly discharged prior to the weekend - results similar to our findings. Similarly, Victory et al demonstrated that the day of surgery influenced LOS for major gynecological surgery. ${ }^{8}$ Contrary to this, Johnson et al reported that day of surgery did not influence LOS with regard to complex neonatal cardiothoracic surgery. Given the complexity of ventricular neonatal reconstructive surgery, postoperative intensive care unit (ICU) admission, and the prolonged complex postoperative course, day of admission is outweighed as a predictor of LOS. ${ }^{16}$

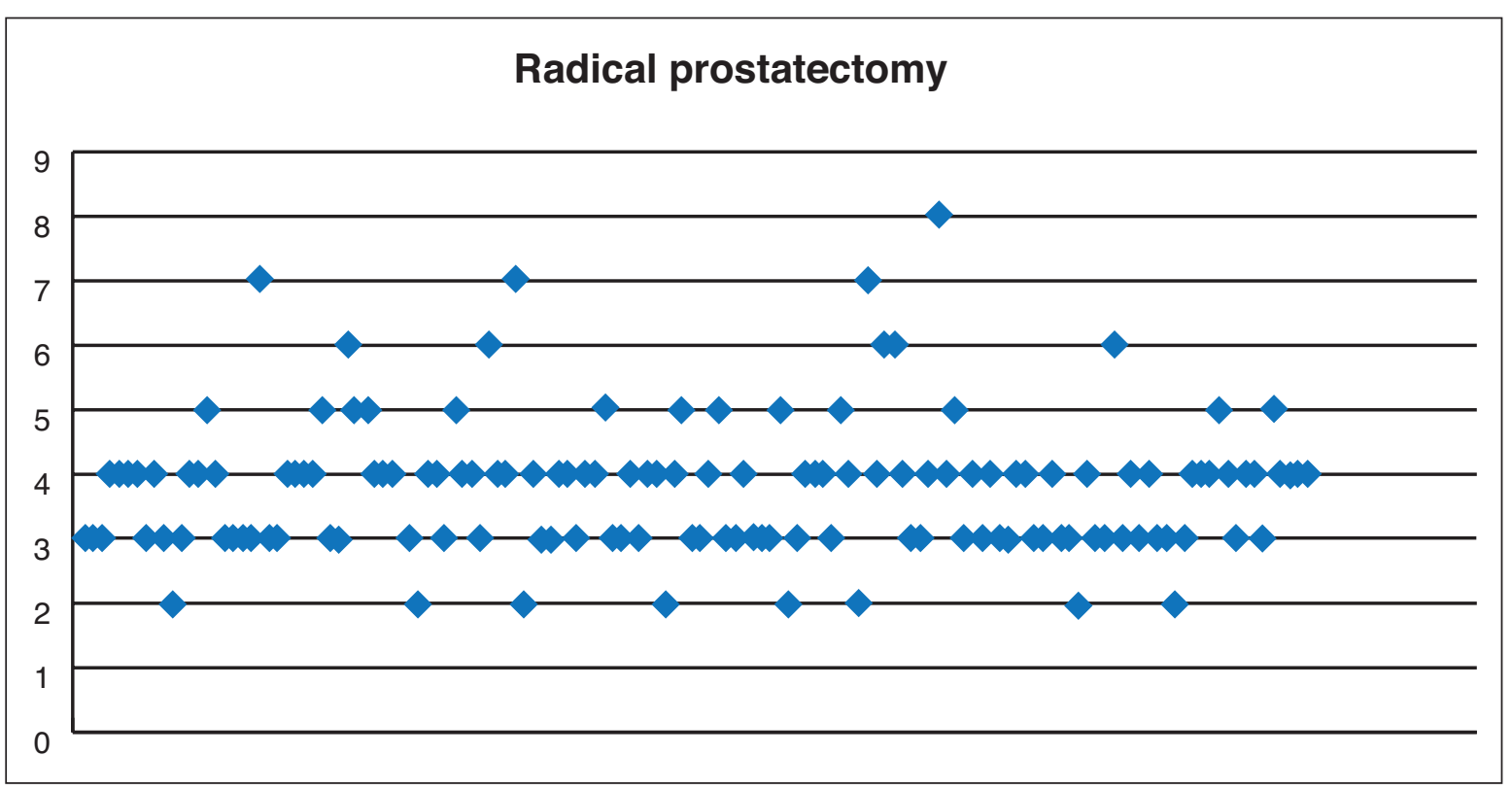

Fig.1. Box plot for length of stay (days) for open radical prostatectomy. 


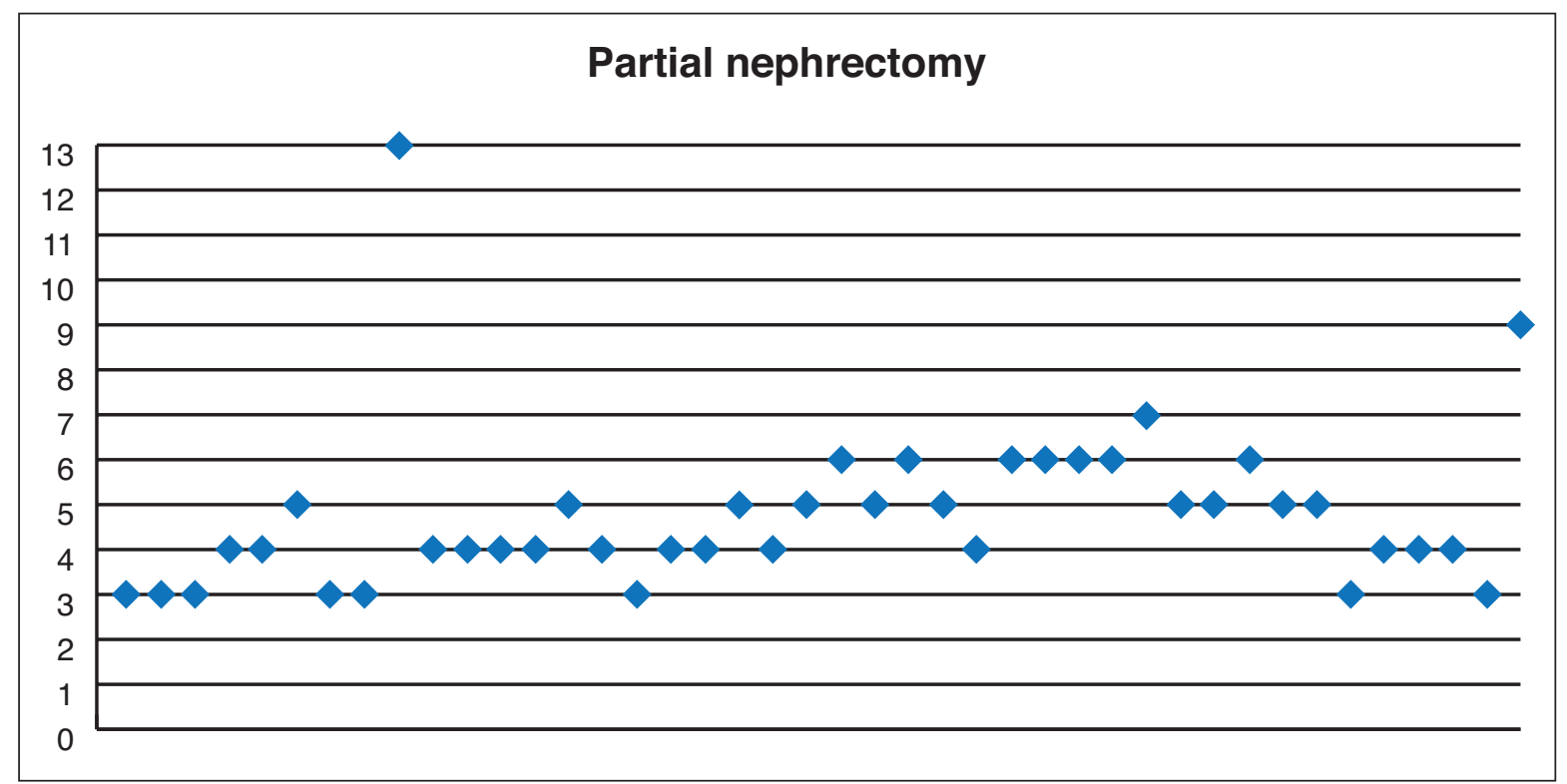

Fig. 2. Box plot of length of stay (days) for open partial nephrectomy.

Several studies pertaining to orthopedic surgery have demonstrated day of surgery impacting LOS. Rathi et al noted a significant increased LOS for elective arthroplasty if surgery was performed on Thursday as opposed to Monday. ${ }^{3}$ Kondo et al demonstrated improved LOS based on day of surgery for hip fractures; however, noted no difference in functional outcomes. ${ }^{17}$ Ricci et al also demonstrated the impact of day of surgery on LOS for hip fracture in geriatric patients. ${ }^{4}$ Orthopedic patients often require physiotherapy regimen prior to discharge and each of these studies highlighted the reduced availability of multidisciplinary resources on the weekend as a potential implicating factor for increased LOS. Maidment et al investigated the change of a physiotherapy service from a five- to seven-day-a-week service for patients post-total knee or hip replacement. They demonstrated the increased availability of physiotherapy treatment was associated with a reduction in the physiotherapy LOS (defined as the number of days physiotherapy was needed in hospital); however, the overall hospital LOS was not reduced. They concluded that this may be due to lack of other administrative aspects of hospital discharge. ${ }^{18}$

Potential reasons for longer LOS in our series involve challenges associated with discharging patients over the weekend, such as transport issues and decreased home supports.

$\begin{aligned} & \text { Table 3. Median (IQR) LOS for two major urological } \\
& \text { procedures performed early (Monday/Tuesday) or late } \\
& \text { (Wednesday-Friday) in the week }\end{aligned}$
\begin{tabular}{lccc}
\hline Procedure & LOS (Early) & LOS (Late) & p value \\
\hline Major procedures & $3(3-4)$ & $4(4-5)$ & 0.0001 \\
Radical prostatectomy & $3(3-4)$ & $4(4-5)$ & 0.0004 \\
Partial nephrectomy & $4(3-5.5)$ & $5(4-5)$ & 0.029 \\
\hline
\end{tabular}

Culturally there are also some superstitions regarding weekend discharges, particularly in elderly rural communities.

ERPs were first introduced by Basse et al to enhance postoperative recovery and avoid common hindrances to early hospital discharge. ${ }^{19}$ ERPs have brought about a dramatic improvement in perioperative care, with a resultant positive impact on LOS. ${ }^{12-14}$ Specialities and institutions have adopted variations of ERP to suit their needs; however, the mainstay of an ERP involves early mobilization, recommencement of diet, and conversion to oral analgesia in an effort to reduce morbidity and improve recovery. Successful ERPs need active collaboration between multidisciplinary team members on the ward supporting patient recovery after surgery. Ihedioha et al noted ERPs were less effective in patients undergoing elective colorectal surgery later in the week, with a two day longer LOS. ${ }^{12}$ Patients in our study all follow a departmental ERP, yet a similar impact on LOS was noted. In our prostatectomy series, the introduction of the ERP was associated with a shortened LOS in the first 25 cases in our series, perhaps due to stricter adherence to the ERP on initiation.

Going forward, we would recommend surgeons consider performing major procedures early in the week, where pos-

\begin{tabular}{lc}
\hline \multicolumn{2}{l}{ Table 4. Median (IOR) LOS for radical prostatectomies } \\
\hline Case number & LOS \\
\hline $1-25$ & $3(3-4)$ \\
$26-50$ & $4(3.5-5)$ \\
$51-75$ & $4(3-4)$ \\
$76-100$ & $4(3-5)$ \\
$101-125$ & $3(3-4)$ \\
$126-140$ & $4(4-4)$ \\
\hline
\end{tabular}

IQR: interquartile range; LOS: length of stay. 


\begin{tabular}{|c|c|c|c|}
\hline & Early & Late & $p$ value \\
\hline $\mathrm{n}$ & 77 & 63 & \\
\hline Age (Mean \pm SD) & $57.3 \pm 5.3$ & $57.8 \pm 5.8$ & 0.59 \\
\hline PSA (Mean \pm SD) & $9.2 \pm 7.5$ & $9.6 \pm 8.7$ & 0.74 \\
\hline Stage (organ-confined) & 47 & 41 & 0.73 \\
\hline Gleason $3+3$ & 16 & 18 & 0.33 \\
\hline Gleason 7 & 60 & 40 & 0.08 \\
\hline Gleason >8 & 1 & 5 & 0.09 \\
\hline
\end{tabular}

sible, so as to benefit from the full arsenal of multidisciplinary resources.

Our study is limited by its retrospective nature of a single surgeon's experience in a single centre. We selected two core procedures to study the effect of day of surgery on LOS; this may not be representative of all major urological procedures. Furthermore, the two studied procedures were open procedures and the day of surgery may not have same impact on laparoscopic or robotic procedures.

\section{Conclusion}

Our findings demonstrate the day of surgery impacts LOS for major urological procedures. Major procedures should be performed early in the week, where feasible, to facilitate prompt, safe discharge and better use of hospital resources.

Competing interests: The authors report no competing personal or financial interests.

This paper has been peer-reviewed.

\section{References}

1. Kostis WJ, Demissie K, Marcella SW, et al. Weekend vs. weekday admission and mortality from myocardial infarction. N Engl J Med 2007;356:1099-109. http://dx.doi.org/10.1056/NEJMoa063355

2. Sheng A, Ellrodt AG, Agocs $L$, et al. Is cardiac test availability a significant factor in weekend delays in discharge for chest pain patients? J Gen Intern Med 1993;8:573-5. http://dx.doi.org/10.1007/ BF02599642

3. Rathi P, Coleman S, Durbin-Johnson B, et al. Effect of day of the week of primary total hip arthroplasty on length of stay at a university-based teaching medical centre. Am J Orthop (Belle Mead NJ) 2014;43:E299-303.

4. Ricci WM, Brandt A, McAndrew $C$, et al. Factors affecting delay to surgery and length of stay for patients with hip fracture. J Orthop Trauma 2015;29:e109-14. http://dx.doi.org/10.1097/ BOT.0000000000000221

\begin{tabular}{|c|c|c|c|}
\hline & Early & Late & $p$ value \\
\hline $\mathrm{n}$ & 24 & 18 & \\
\hline Age (Mean \pm SD) & $50.3 \pm 13.6$ & $56.9 \pm 10.8$ & 0.09 \\
\hline Sex (M:F) & $16: 8$ & 8:10 & 0.21 \\
\hline Tumour size (Median IQR) & $3.35(2.9-5.8)$ & $3.2(2.1-4.3)$ & 0.31 \\
\hline Stage (organ-confined) & 23 & 18 & 1.00 \\
\hline Side $(L: R)$ & $13: 11$ & $9: 9$ & 1.00 \\
\hline
\end{tabular}

F: female; IQR: interquartile range; L: left; M: male; R: right; SD: standard deviation.

5. Gilmore DM, Curran T, Gautam S, et al. Timing is everything: Colectomy performed on Monday decreases length of stay. Am J Surg 2013;206:340-5. http://dx.doi.org/10.1016/i.amisurg.2012.11.014

6. Hsu JC, Varosy PD, Parzynski CS, et al. Procedure timing as a predictor of in-hospital adverse outcomes from implantable cardioverter-defibrillator implantation: Insights from the National Cardiovascular Data Registry. Am Heart J 2015;169:45-52.e3. http://dx.doi.org/10.1016/j.ahi.2014.10.006

7. Tadisina KK, Chopra K, Singh DP. The "weekend effect" in plastic surgery: Analyzing weekday vs. weekend admissions in body contouring procedures from 2000 to 2010. Aesthet Surg J 2015;35:995-8. http:// dx.doi.org/10.1093/asi/siv088

8. Victory R, Carey MS, Stitt L. Predictors of length of stay for inpatients having benign gynecological surgery. J Obstet Gynaecol Can 2005;27:43-50. hittp://dx.doi.org/10.1016/S1701-2163(16)30171-2

9. Barba R, Zapatero A, Losa JE, et al. The impact of weekends on outcome for acute exacerbations of COPD. Eur Respir J 2012;39:46-50. http://dx.doi.org/10.1183/09031936.00013211

10. Aujesky D, Jiménez D, Mor MK, et al. Weekend vs. weekday admission and mortality after acute pulmonary embolism. Circulation 2009;119:962-8. http://dx.doi.org/10.1161/CIRCULATIONAHA.108.824292

11. Hamaguchi S, Kinugawa S, Tsuchihashi-Makaya M, et al. Weekend vs. weekday hospital admission and outcomes during hospitalization for patients due to worsening heart failure: A report from Japanese Cardiac Registry of Heart Failure in Cardiology (JCARE-CARD). Heart Vessels 2014;29:328-35. http:// dx.doi.org/10.1007/s00380-013-0359-5

12. Thedioha U, Esmail F, Lloyd G, et al. Enhanced recovery programmes in colorectal surgery are less enhanced later in the week: An observational study. JRSM Open 2015;6:2054270414562983. http://dx.doi. org/ $10.1177 / 2054270414562983$

13. Daneshmand S, Ahmadi H, Schuckman AK, et al. Enhanced recovery protocol after radical cystectomy for bladder cancer. J Urol 2014;192:50-5. http://dx.doi.org/10.1016/i.juro.2014.01.097

14. Dutton TJ, Daugherty MO, Mason RG, et al. Implementation of the Exeter enhanced recovery program for patients undergoing radical cystectomy. BJU Int 2014;113:719-25. http://dx.doi.org/10.1111/ bju. 12533

15. Diblasio CJ, Snyder ME, Russo P. Mini-flank supra-1 1 th rib incision for open partial or radical nephrectomy. BJU Int 2006;97:149-56. http://dx.doi.org/10.1111/i.1464-410X.2006.05882.x

16. Johnson JT, Sleeper LA, Chen $S$, et al. Associations between day of admission and day of surgery on outcome and resource utilization in infants with hypoplastic left heart syndrome who underwent stage I palliation (from the Single Ventricle Reconstruction Trial). Am J Cardiol 2015;116:1263-9. http:// dx.doi.org/10.1016/i.amicard.2015.07.044

17. Kondo A, Yamaguchi C, Fujimoto E. Relationship between admission day and timing of surgery for patients with hip fracture. Jpn I Nurs Sci 2014;11:248-58. http://dx.doi.org/10.1111/iins.12026

18. Maidment ZL, Hordacre BG, Barr CJ. Effect of weekend physiotherapy provision on physiotherapy and hospital length of stay after total knee and total hip replacement. Aust Health Rev 2014;38:265-70. http://dx.doi.org/10.1071/AHI3232

19. Basse L, Thorbol JE, Loss $K$, et al. Colonic surgery with accelerated rehabilitation or conventional care. Dis Colon Rectum 2004;47:271-7. http://dx.doi.org/10.1007/s10350-003-0055-0

Correspondence: Dr. Gregory Nason, Specialist Registrar in Urology, Cork University Hospital, Cork, Ireland; nasong@tcd.ie 